\title{
Digitalisation Trends and Blended Learning Visualisation in Modern Digital Education
}

\author{
Andrew V. Danilov, Leila L. Salekhova, Nigina B. Tursunova, Nnamdi Anyameluhor
}

\begin{abstract}
The article under review actualizes the problem of using digital computer technologies in the process of blended learning. The notion of «blended learning» is determined and specified according various sources. Various models and ways of organizing this kind of work as an alternative to the standard form of learning are presented. The article presents the positive experience of using blended learning technology. Attention is paid to visualization as one of teaching tool to create educational materials for blended learning. Synthesis of verbal (especially word) and visual elements (pictures, graphic notes, animations, films, plots and diagrams, etc.) within the limits of one text's space is an instrument of optimization of the process of semantic perception and understanding text information. All benefits of this modern technology allows to establish a holistic adoption of this model by students and the positive direction for the development of blended learning as an innovative teaching technology.
\end{abstract}

Keywords: visualization, blended learning, e-learning, digital education.

\section{I.INTRODUCTION}

Digital technology is a unique mechanism for the all-round development of a modern educational organization. Due to the use of digital technologies, there is a potential for the rapid exchange of experience and knowledge among interested persons and the progress of digital libraries. The range of subjects who receive unique information that was previously available only to a narrow circle of experts and scientists is expanding. Furthermore, due to use of digital technologies, we can confidently talk about the globalization of the scientific world and the active development of academic mobility.

It should be emphasized that the trends of globalization and the growing proportion of online educational services in the additional education area can drastically change the traditional system of education. Digital educational resources become the basis for the development of information educational services. It should be noted that digitization of the education system has particular relevance in the additional education area either further training courses or language study.

When we talk about getting a first, basic higher education, a modern university should have a combination of both modern information technologies and direct communication students

Revised Manuscript Received on November 08, 2019.

* Correspondence Author

Andrew V. Danilov, Kazan Federal University, Institute of Philology and Intercultural Communications

Leila L. Salekhova, Kazan Federal University, Institute of Philology and Intercultural Communications

Nigina B. Tursunova, Kazan Federal University, Institute of Philology and Intercultural Communications

Nnamdi Anyameluhor, Nottingham Trent University (Great Britain), Department of Computing and Technology with teachers, experts, and scientists. It would be quite productive to replace the standard set of theoretical lectures with online products and to increase the number of hours aimed at holding workshops, developing practical and project activities to university students.

Of course, digital transformation will also play a special role in the strategic renewal of a modern high school. It is important to organically use information resources and technological solutions in the management of the educational process either full-time education or distance learning. Experience has shown that the widespread use of digital technologies and the replacement of a "living" teacher does not lead to the desired effect. In such a situation, technologies and approaches that combine digital technologies and face-to-face classes with a "living" teacher came to the fore. One of these is blended learning technology.

The aim of this article: to show the positive experience with the application of blended learning technology on the example of implementation visualization technologies into the education process.

\section{METHODS}

The term "blended learning" originated in the corporate environment about 30 years ago. In the 1980s, Boeing began using multimedia materials (CDs and video films) for on-the-job training course to improve the qualifications of its own staff members. The positive experience of the company was noticed by other companies and was used in cases of students had difficulties with combining work and learning $[1,2]$.

With the rise of digital technology, this training model has become more widespread. There was an idea of a complete replacement of the "living" teacher with the computer. However, such an idea did not receive adequate support, since e-learning prevent students from developing their social, cultural and speech skills at the proper level.

In such circumstances, the term "blended learning" (blended learning) was coined. The student gains knowledge both in person, communicating live with peers and teachers, as well as independently, using modern information technologies at a pace that will be comfortable for the student.

It is necessary to distinguish the concepts "blended learning" and "distance learning". In distance learning models the student receives almost no help from the teacher, and full-time classes are used, as a rule, only for conducting knowledge control.

The term "blended learning" was used extensively with the publication of the first Handbook of Blended Learning: Global Perspectives, Local Designs by Curtis Bonk and Charles Graham in 2005 [3]. In research literature there are some other terms with slightly 
shifted accents as "hybrid learning", "technology-mediated instruction", "web-enhanced instruction", and "mixed-mode instruction" that are often used interchangeably.

The most actively blended learning technology is developing in the United States. If in 2000 the technology of blended learning was available only to 45 thousand American schoolchildren, then in 2009 their number reached three million. By 2019, 50\% of all school lessons are planned in mixed mode in the United States.

There are distinct blended learning models suggested by some researchers and educational think-tanks. These models include [4]:

- Face-to-Face Driver. The material is transferred from the teacher to the pupils in the classroom. Electronic resources are used only to consolidate and deepen knowledge.

- $\quad$ Online Driver. The student watches webinars, solves online problems, passes Internet testing, that is, masters the material remotely. But if necessary, students can meet with the teacher and consult on incomprehensible issues.

- Flex model. The main part of the program is presented online. The teacher acts as a coordinator, monitoring difficult to understand topics, then to discuss them in a group or individually.

- $\quad$ Rotation model. Full-time and online learning alternate: first, students study the materials independently via the Internet, then with the teacher in the classroom, and vice versa.

- $\quad$ Self-blend. Students go through the program as usual. But, if certain subjects are of increased interest, you can take additional online classes.

- $\quad$ Online Lab. All of the curriculum is delivered via a digital platform but in a consistent physical location. Students usually take traditional classes in this model as well.

In pure form, these models are rarely used. Usually they are combined. For example, Face-to-Face with Flex: in addition to attending classes, students independently study the materials online, and then discuss unclear moments with the teacher.

According to the estimates of the consortium "Sloan" (The Sloan Consortium), more than $60 \%$ of American students think that blended learning more effective than traditional learning the subjects. It's easy to believe, looking at the pros of blended learning technology [5].

Flexibility of the educational process. It can involve any number of teachers and students. Teachers can give master classes, even being on another continent, and you can refer to electronic educational materials at any time and from any place.

Openness of learning. Taking exams on the computer, it is difficult to write off or face bias from the teachers. Also, communication technologies allow students and teachers to constantly support feedback, and thus better understand each other.

Individual approach. Teachers can vary the pace and the amount of learning materials depending on the personal characteristics of students. A combination of different models allows each student to develop in the direction that he is interested in.

Development of independence. The student has to effectively manage their time, be able to plan and be disciplined. Otherwise, a mixed system will never succeed.

Increase motivation. Many people like gadgets and services. In the XXI century people do not just want to learn - they want the training and learning shall preferably be interactive and interesting. In today's reality students gladly participate in webinars, conduct discussions on forums, master various computer programs.

\section{RESULTS AND DISCUSSION}

Consider the visualization technology as one of teaching tool to create educational materials for blended learning. Visualization is the process of presenting content as an image in order to provide the in-depth understanding of the outputs. Visualization technology includes:

- $\quad$ giving a visible form to any conceivable object, subject, process, etc.;

- mechanical image induction;

- the formation of clear and vivid images of any complexity and specificity (both actually existing and created in the mind of the author) with the help of technical devices or mental images directly in your mind (mental visualization).

- $\quad$ Based on the above, a technology of visualization of educational information has emerged - this is a system that includes the following components:

- complex of educational knowledge; visual presentation methods;

- $\quad$ visual technical tools of information transfer;

- a set of psychological techniques for the use and development of visual thinking in the learning process.

It was necessary to visualize the learning content in order to minimize the cognitive and linguistic difficulties encountered by the students. The process of visualization is a very important process of creating educational material. Visualization involves the use of a visual form of knowledge representation (abstract signs, visual diagrams, specific objects, etc.) instead of / with verbal support. The use of visual elements, according to R. Skemp, contributes to the development of conceptual knowledge of the students. The acquisition of conceptual knowledge enriches students not only with knowledge of what to do and how to do, but also the ability to do it practically, with a high level of performance [6].

Information visualization provides to students to comprehend more effectively the relations within study subject. Thus, visualization can be considered as an effective way of understanding a text content in the context of self-learning, especially in courses where blended learning is used.

\section{IV.SUMMARY}

Consider the use of visual elements on the example of the educational course "Web-developing". This resource was created as support for the "Technical devices in professional activity" course, which was included to "Teacher of Mathematics and Computer Science" profile program [7-13-14].

The course was designed and published on the Moodle learning management system. Despite the Moodle LMS is used mainly for distance education, this course is used with blended learning model: students learn course curriculum themselves, and in addition discuss issues with the teacher and work with the resource during full-time classes.

First, a wide range of visual materials was used in the 
development of this digital course:

- Computer presentations. Presentations contain static images and accompanying text. Content in this case plays the role of theses and allows the student to focus on the core facts. Presentations allows students to choose for themselves the pace of work.

Animated material. Unlike static images, animation allows students to show dynamic processes. This is especially important in a course such as programming, where many work procedures (in particular, the course of work of a running program) change over time - motions of geometric shapes, changes in text properties, etc. Also screencasting is used in the course content. Screencasting is a type of video broadcasting that allows a video stream with a record of what is happening on a user's computer to be transmitted to a wide audience. [15]. The teacher's actions are recorded from a computer program (for example, selecting the necessary function in the program interface, performing a series of operations), after which the recorded fragment is mounted and inserted into the lesson. This solution allows you to get rid of redundant verbal commenting.

- Interactive materials. This type of content is characterized by the fact that the student can interact with it. Interactive visualized materials allow the teacher to transmit information about the objects, processes and phenomena under study. These materials include various interactive learning games, demonstrations, tasks, etc.

Secondly, a digital video library consisting of fragmentary educational films and film fragments for use in the educational process has been compiled in a digital resource. Video information has a high degree of emotional impact and, thus, contributes to the rapid absorption of educational material [8-12].

\section{V.CONCLUSION}

Visualization in blended learning allows you to solve a whole range of pedagogical tasks: providing the intensification of teaching; enhancing learning and cognitive activities; developing critical and visual thinking, visual perception, imaginative representation of knowledge and educational actions, knowledge transfer and pattern recognition; improvement of visual literacy and visual culture. Methodically competent approach to visualization ensures and supports the transition of the students to a higher level of cognitive activity, stimulates the creative approach. Modern technologies allow to solve the problems such as educational information transfer, building skills and competencies, as well as automated control of knowledge.

The didactically verified use of visual images in computer science training can turn visibility from auxiliary, illustrating means into a leading, productive methodical tool that contributes to the building students' information culture.

\section{AKNOWLEDGEMENTS}

The work is performed according to the Russian Government Program of Competitive Growth of Kazan Federal University.

\section{REFERENCE}

1. M. Oliver, "Trigwell K. Can 'Blended Learning' Be Redeemed?", E-Learning. vol. 2 (1), 2005, pp.17-26.

2. J. Bersin. "How Did We Get Here? The History of Blended Learning", The Blended Learning Book: Best Practices, Proven Methodologies, and Lessons Learned". Wiley: 2004.

3. C. Bonk, C. Graham. "The Handbook of Blended Learning: Global Perspectives, Local Designs”. John Wiley \& Sons, Inc. Pfeiffer:2006, P. 624

4. "6 Models of Blended Learning". URL http://www.dreambox.com/blog/6-models-blended-learning

5. I. Allen, J. Seaman, R. Garrett. "Blending In: The Extent and Promise of Blended Education in the United States": Sloan-C, 2007, P. 35.

6. R. Skemp. "Relational Understanding and Instrumental Understanding. Mathematics Teaching in the Middle School". vol. 122, 2006, pp. 8895-8901.

7. Электронный образовательный ресурс"Web-developing". URL: https://do.kpfu.ru/course/view.php?id=3499

8. N. Batrova, M. Lukoyanova, L. Salekhova, G. Çavuşoğlu. "Booktrailer como medio de formar la competencia discursiva de los estudiantes" Revista Científica Electrónica de Ciencias Humanas / Scientific e-journal of Human Sciences:Fundación Unamuno, vol. 14, 2018, pp. 223-231

9. Syunina, A. S., Yarmakeev, I. E., Shechter, D. A., Pimenova, T. S. \& Abdrafikova, A. R. Text relevance as a valid criterion for selecting reading materials for forming reading skills in EFL class // Modern Journal of Language Teaching Methods, 2017. -p.166

10. I. Salpykova, R. Akhmadullina, N. Valiakhmetova PREPARATION OF THE FUTURE TEACHERS FOR IN CHILDREN'S HEALTH CAMPS /EDULEARN18, the 10th annual International Conference on Education and New Learning Technologies will be held in Palma de Mallorca (Spain), 2018 Pages: 2329-2336

11. Solnyshkina, M.I., Zamaletdinov, R.R., Gorodetskaya, L.A., Gabitov, A.I. Evaluating text complexity and Flesch-Kincaid grade level Journal of Social Studies Education Research 8(3), c. 238-248

12. Selomo, M. R., \& Govender, K. K. Procurement and Supply Chain Management in Government Institutions: A Case Study of Select Departments in the Limpopo Province, South Africa. (2016).

13. Marques, B. P., Villate, J. E., \& Carvalho, C. V. Student Activity Analytics in an e-Learning Platfom: Anticipating Potential Failing Students. Journal of Information Systems Engineering \& Management, 3(2), (2018). 12.

14. Mazana, M. Y., Montero, C. S., \& Casmir, R. O. Investigating Students' Attitude towards Learning Mathematics. International Electronic Journal of Mathematics Education, 14(1), (2019). 207-231. https://doi.org/10.29333/iejme/3997

15. Bakhyt, S., Kalimbetov, B., \& Khabibullayev, Z. Possibilities of mathematical problems in logical thinking. Development of secondary education pupils. Opción, 34(85-2), (2018). 441-457. 